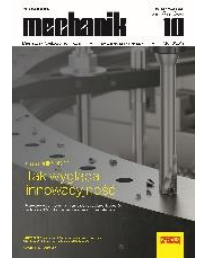

How to cite this article:

Authors: Maciej Kowalski, Marek Kołodziej, Hubert Skowronek

Title of article: „P Possibilities of using a wavelet transform to assess the surface conditions of abrasives belts”

Mechanik, No. 10 (2019)

DOI: https://doi.org/10.17814/mechanik.2019.10.87

\title{
Possibilities of using a wavelet transform to assess the surface conditions of abrasives belts
}

\author{
MACIEJ KOWALSKI \\ MAREK KOŁODZIEJ \\ HUBERT SKOWRONEK *
}

Dr inż. Maciej Kowalski, maciej.kowalski@pwr.edu.pl, https://orcid.org/0000-0003-3413-8334 - Katedra Obrabiarek i Technologii Mechanicznych Politechniki Wrocławskiej, Wrocław, Polska

Dr inż. Marek Kołodziej, marek.kolodziej@ pwr.edu.pl, https://orcid.org/0000-0001-6916-8520 - Katedra Obrabiarek i Technologii Mechanicznych Politechniki Wrocławskiej, Wrocław, Polska

Dr inż. Hubert Skowronek, hubert.skowronek@pwr.edu.pl, https://orcid.org/0000-0003-3398-1661 - Katedra Obrabiarek i Technologii Mechanicznych Politechniki Wrocławskiej, Wrocław, Polska

Issues regarding the application of wavelet analysis to the description of the surface condition of abrasive tools differing in grain size and construction method are presented. New tools were tested and after the specified grinding time.

KEYWORDS: roughness, abrasive belts, grinding, surface layer

\section{Introduction}

Wavelet analysis comes from the classic Fourier signal decomposition technique. Value of the interval and amplitude of the wavelet functions analyzed results from the value of adopted scale and shift results. The wavelet property is a similarity obtained due to the scaling process at all levels of analysis. If the signal is a roughness profile, the wavelet transform divides it into the sum of perpendicular component signals. This procedure allows for the analysis of individual signal components at different spatial resolutions.

The wavelet is a mathematical function, the good time and frequency localization of which results from its characteristics: zero mean value and finite signal strength. The wavelet also takes zero values outside a given finite range.

The term 'wavelet' comes from short-term oscillations, in which information on various levels of detail is given. A well-chosen wavelet can remove noise and interference from the analyzed signal.

Correct wavelet analysis involves choosing the right mother wavelet and the scaling function, i.e. the wavelet analyzing function. The better the fit of the shape of the function to the signal being examined, the smaller number of functions is needed for approximation. The most important factor is the similarity of the shape of selected wavelet to the analyzed signal $[2,6-8]$.

The use of wavelet analysis to assess the surface after machining processes is used to detect such anomalies on the surface profile of the surface being tested that cannot be detected using standard Gaussian analysis. Wavelet analysis also provides information on all extremes and their distribution for roughness and waviness. It can be used for: detection of catastrophic blunting of the blade, abrupt change of allowance, vibration diagnostics, roughness analysis, force analysis, chip recognition, blade wear assessment.

\section{Research methodology}

High-chromium steel X17CrNi16-2, belonging to stainless and acid-resistant steels, was used in the tests. This material is used in the aviation, petrochemical, petroleum and food industries, for the production of soap and acid. It is used to make elements such as sleeves, rollers, pins, gears.

A $50 \mathrm{~mm}$ diameter roller was prepared for testing. The tests were carried out on a universal lathe after installing a special adapter used to guide abrasive belts in the tool post. Grinding of individual shaft segments (with cutting speed $v c=25 \mathrm{~m} / \mathrm{s}$ ) was carried out with a free part of abrasive bands of various grain sizes ranging from tapes with artificial corundum embankment marked P40, through tapes P60 and P80, to tapes P100. 
The 3M Trizact abrasive belts with A30 and A65 granulation were also used in the tests. They differ from ordinary tapes in the way they are made. The pyramid structure of the abrasive grains, which are spaced at an equal distance, causes that new, sharp abrasive particles are exposed during processing. As a result, the material is machined evenly, which guarantees a uniform surface finish.

The surface condition of abrasive belts was examined before and after machining. Roughness measurements were made on a Taylor Hobson Form Talysurf 120L profilograph. Because high values of the analyzed roughness parameters were expected, a measuring section of $40 \mathrm{~mm}$ and an elementary section of $8 \mathrm{~mm}$ in length were adopted, which corresponds to the recommendations in PN-EN ISO 3274 and 4288. The measurement was performed with a conical measuring needle with an opening angle of $90^{\circ}$ and a rounding radius tip of $5 \mu \mathrm{m}$.

\section{Results}

Measurements provided information on the surface roughness parameters of individual new belts and after one minute of grinding the stainless steel. Values of the measured parameters are given in the table.

TABLE. Roughness parameters measured on the surfaces of tested abrasive belts

\begin{tabular}{|c|c|c|c|c|}
\hline \multirow{2}{*}{ Belt designation } & \multicolumn{4}{|c|}{ Roughness parameters } \\
\cline { 2 - 5 } & \multicolumn{2}{|c|}{ Before machining } & \multicolumn{3}{c|}{ After maching } \\
\cline { 2 - 5 } & $R a[\mu \mathrm{m}]$ & $R z[\mu \mathrm{m}]$ & 55.3 & 273.9 \\
\hline P40 & 74.4 & 344.7 & 43.8 & 210.6 \\
\hline P60 & 59.6 & 270.9 & 24.7 & 157.7 \\
\hline P80 & 37.7 & 193.7 & 21.3 & 138.5 \\
\hline P100 & 32.5 & 153.2 & 30.7 & 158.2 \\
\hline A30 & 43.8 & 187.5 & 23.3 & 132.2 \\
\hline
\end{tabular}

For the wavelet analysis of profiles reflecting the roughness of the examined abrasive embankment tools, the MATLAB computer program was used, characterized by a large number of library functions and the ability to write own functions and programs using an internal programming language [5].

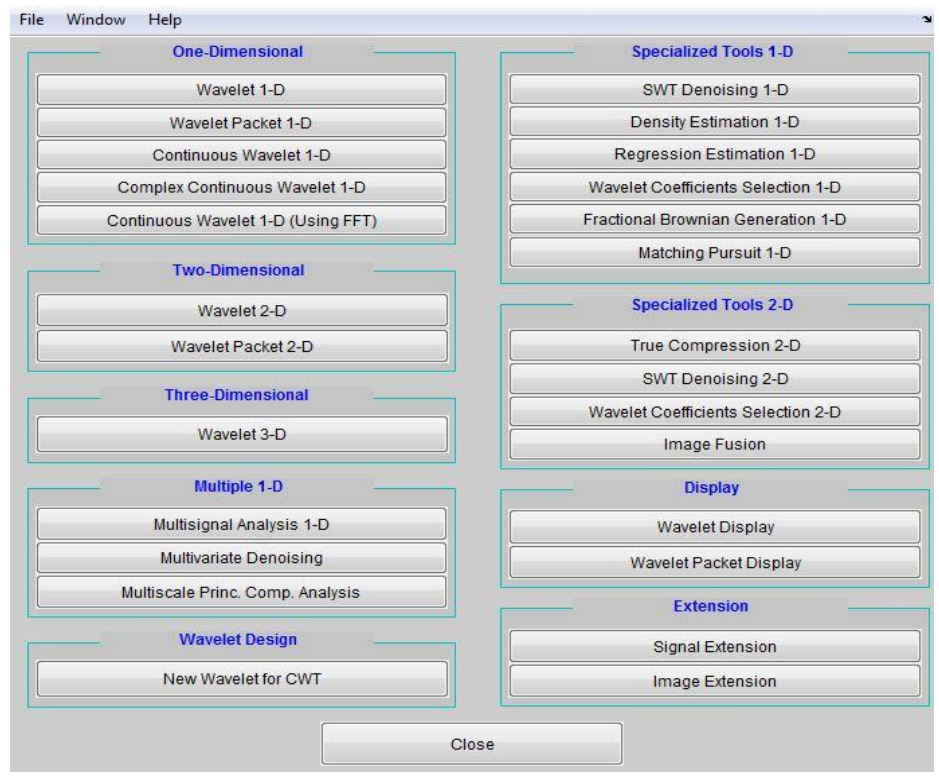

Fig. 1. Wavelet Toolbox window

After loading the selected signal, specify the wavelet type and scale, for which the analysis will be carried out. One must also specify the number of steps, after which the scale value should change. The parameters selected for the CTF (continuous wavelet transform) analysis are shown in fig. 2.

It is worth remembering that the basis for the proper use of the wavelet transform is the selection of appropriate wavelets for signal analysis. This selection depends on the properties of individual wavelets or their similarity to the tested signal.

The type of wavelet was selected after conducting experimental analyses (using different types of wavelets) of fragments of roughness profiles measured on new belts, without signs of wear. Results obtained for different 
wavelets were compared visually with each other in search of the most obvious signs of instability of the measured signal. When choosing the wavelet, recommendations included in the literature were also used - according to them, for the assessment of non-linear signals, they are well-suited, among others, Mexican hat and Morlet wavelets [7]. The first one allows to get information about the values and distribution of signal extremes, but does not say anything about the length of the wavelet components. When using the Morlet wavelets, one can get information on wavelengths, while information about amplitude values is not accurate. Accurate analysis therefore requires the use of at least two continuous wavelet transforms, in which different wavelets will be used [1-4]. This paper presents only selected results of CTF analyses of uneven profiles found on embankment abrasive tools. Fig. 3 presents the results of CTF analysis for the P40 tape, and fig. 4 - for the Trizact A30 tape.

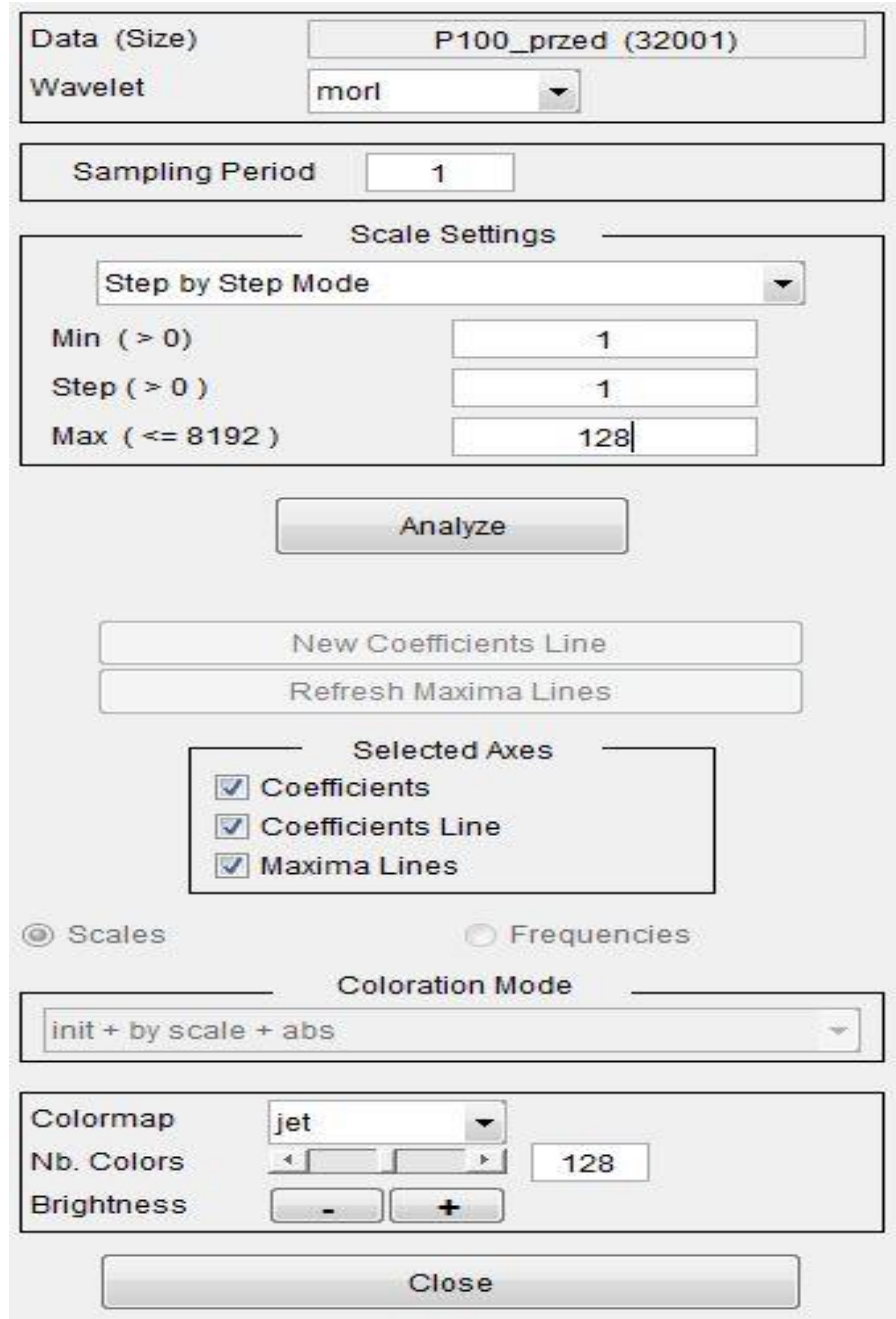

Fig. 2. Ability to set CTF analysis parameters

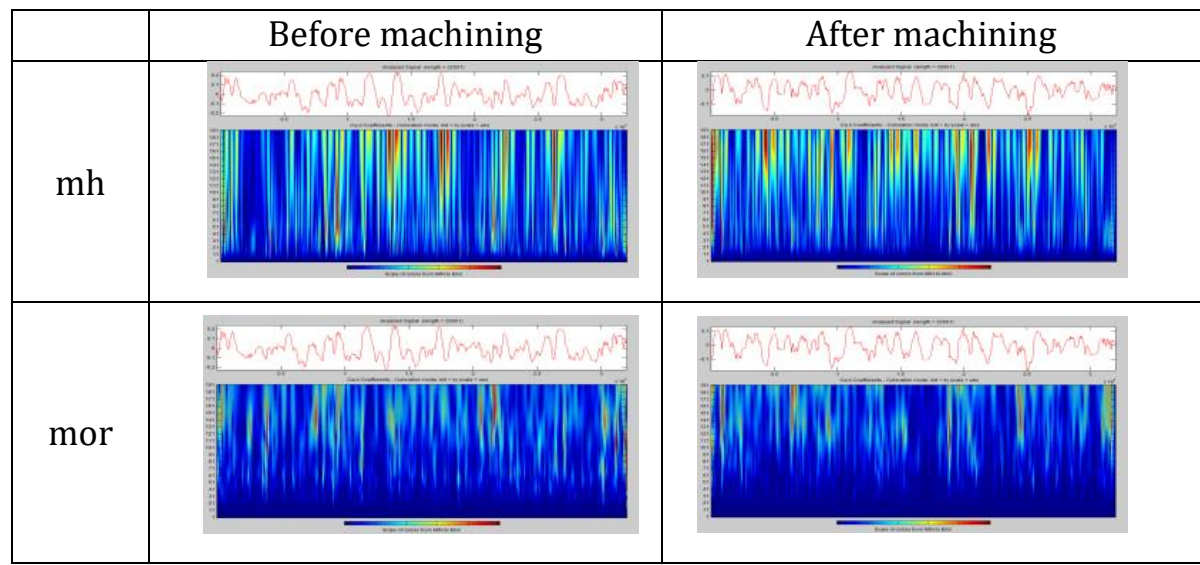

Fig. 3. Continuous wavelet transform for P40 tape ( $\mathrm{mh}$ - Mexican hat wavelet, mor - Morlet wavelet) 


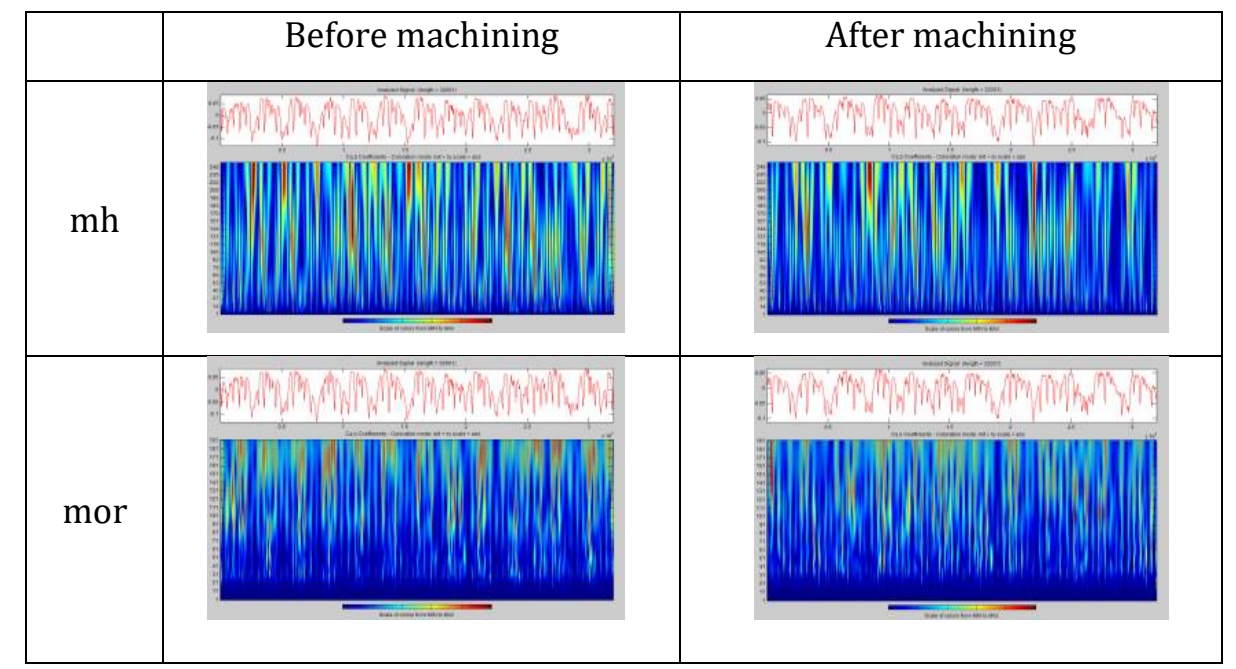

Fig. 4. Continuous wavelet transform for Trizact A30 tape ( $\mathrm{mh}$ - Mexican hat wavelet, mor - Morlet wavelet)

After analyzing the roughness profile of the P40 tape with a continuous wavelet transform using the Mexican hat wavelet, one can notice the distribution and values of the profile extremes. These are fields other than blue. The most intense red indicates places where the profile extremes occur. They reach values around 13500 on the profile, where there is the largest depression in the studied section. A similar situation occurs around 17800. Another extreme is visible near 26000. Analysis of the CTF profile obtained after using the Morlet wavelet indicates two bands: the first - short-term on a scale of $45 \div 70$, the second - with a lower frequency begins with scale 100.

In the analysis of the roughness profile measured on a P40 tape, which worked for a minute, the use of a Mexican hat wavelet showed more function extremes than before machining. Many of these extremes are at similar levels, with two largest ones being found around 8000 and 20500 sample points. When Morlet wavelet was used, no clear band was recorded.

The analysis of the profile of the unused Trizact A30 tape, applying a continuous wavelet transform with a Mexican hat wavelet, indicates that the highest extremes are found in the places of the largest depressions of the profile, i.e. around the 2500,5000 and 15300 sampling point. After testing the signal with a Morlet wavelet, two bands were noticed: the first in the $25 \div 45$ scale range and the second in the $70 \div 100$ scale range. The repeatable scale size of every 2500 points of the analyzed profile is also visible, which may indicate the regularity of arrangement of structures forming the abrasive embankment on the tested belt.

After testing with a Trizact A30 grinding belt and performing a CTF analysis with a Mexican hat wavelet - as in the case of unused belt - the highest extremes were detected at the points of the largest pits, and above all around the 8500 and 20200 point of the tested sample. The continuous wavelet transform using Morlet wavelet shows one band located in the same place as in the case of the profile measured on the tested belt before machining. Therefore, it is probably a component associated with periodically recurring cavities occurring on the ordered structures of the Trizact type embankment.

The use of Mexican hat wavelet and continuous wavelet transform revealed slow wear of grains in the contact zone with the workpiece, i.e. the grains protruding most from the binder, on the P40 embankment tape progressing with machining. Extremes appearing on the profile are more visible and their values begin to approach each other. It is probably caused by the progressive abrasive wear of the highest-placed grains, which in belts with standard embankment are subject to abrasion, revealing subsequent, less protruding abrasive grains. The elevation heights of the profile thus achieve similar values, which results in lower values of the function extremes. The lowest profile hollows remain the most visible, for which CTF reaches the highest values.

Analyzing the results of continuous wavelet transforms with the use of Morlet wavelets before and after surface machining with Trizact embankment tape, it can be concluded that in the case of the new tape, there are visible - every defined, constant number of measuring points - repeatable scale values. On the other hand, on belts for which the abrasive wear process has begun, finding similar regularity is much more difficult to detect. Individual band boundaries become blurred and the wavelengths take similar values throughout the entire measuring distance analyzed.

Mexican hat wavelet used for continuous wavelet analysis of tools with changing grain size used for the abrasive embankment, strongly emphasizes the differences in the distribution of extremes of function. In the case 
of tapes marked P40, a small number of extremes can be seen, while the grain size used for the abrasive embankment decreases, the number of extremes is constantly increasing, which was especially visible in the shortwave wavelet band - as for the P100 tape. This is mainly due to the decreasing grain size. In this case, the grains are more densely arranged, which causes more frequent occurrences of extremes related to the density of hills and pits on the profile being assessed.

In the case of a continuous wavelet transform using Morlet wavelets, it can be seen that as the grain size used for the abrasive embankment decreases, the number and size of individual profile wavelets also increase. In addition, short-term wavelengths were observed for belts with finer grains (P80 and P100) and for belts with a certain regularity of embankment arrangement (Trizact A30 and A65).

\section{Summary}

Analyzing the results obtained after applying different types of wavelets, it should be stated that in order to obtain as complete information about the surface as possible, it is necessary to use at least two different types of wavelets, one of which provides data on the values of extremes and their distribution on the studied profiles, the other - data about the length of components or possible disturbances and the intensity of their occurrence at the interface of the grain and the workpiece.

Since the continuous wavelet transform requires a lot of computational effort, it seems reasonable to conduct research on the quality of the surface condition description of the abrasive tool - also using a discrete variation of wavelet analysis. In this analysis, scale factors and shifts are based on the power of two. Discrete wavelet analysis is based on the theory of multi-resolution analysis, in which a pair of low-pass and high-pass filters (the so-called two-channel sub-band encoder) is used [5]. With this approach, any signal can be decomposed into a low-frequency component representing the overall signal waveform and a high-frequency component representing the detailed signal features. In this case, the decomposition process is iterative, thus one signal can be broken down into many smaller elements and be a source of additional information about the state of the abrasive tool.

\section{REFERENCES}

[1] Augustyniak P. „Transformacje falkowe w zastosowaniach elektrodiagnostycznych”. Kraków: Uczelniane Wydawnictwo AGH, 2003.

[2] Białasiewicz J.T. „Falki i aproksymacje”. Warszawa: Wydawnictwa Naukowo-Techniczne, 2004.

[3] Grzesik W., Brol S. "Wavelet and fractal approach to surface roughness characterization after finish turning of different workpiece materials". Journal of Materials Processing Technology. 209 (2009): 2522-2531.

[4] Hennel J.W. „Jak zrozumieć falki. Podstawy falkowej analizy sygnałów”. Kraków: ZamKor, 2010.

[5] Misiti M., Misiti Y. Oppenheim G., Poggi J-M. „Wavelet Toolbox for use with Matlab”. The MathWorks, Inc. 1997.

[6] Timofiejczuk A. „Metody analizy sygnałów niestacjonarnych”. Gliwice: Wydawnictwo Politechniki Śląskiej, 2004.

[7] Wojtaszczyk P. „Teoria falek”. Warszawa: Wydawnictwo Naukowe PWN, 2000.

[8] Zawada-Tomkiewicz A. „Analiza obrazu powierzchni obrobionej do celów estymacji parametrów tej powierzchni". Acta Mechanica et Automatica. 1, 2 (2007). 